\title{
New Trend of Biomarkers: Epigenetic Biomarkers
}

\author{
Ugur Ozkan ${ }^{1,4}$, Mustafa Yildiz ${ }^{2 *}$ and Metin Budak ${ }^{2,3}$ \\ ${ }^{1}$ Faculty of Medicine, Department of Cardiology, Turkey \\ ${ }^{2}$ Faculty of Medicine, Department of Biophysics, Turkey \\ ${ }^{3}$ Molecular Research Lab, Prof. Mirko Tos Ear and Hearing Research Center, Turkey \\ ${ }^{4}$ Murat State Hospital, Department of Cardiology, Edirne, Turkey \\ *Corresponding author: Mustafa Yildiz, Faculty of Medicine, Department of Biophysics, Edirne, Turkey
}

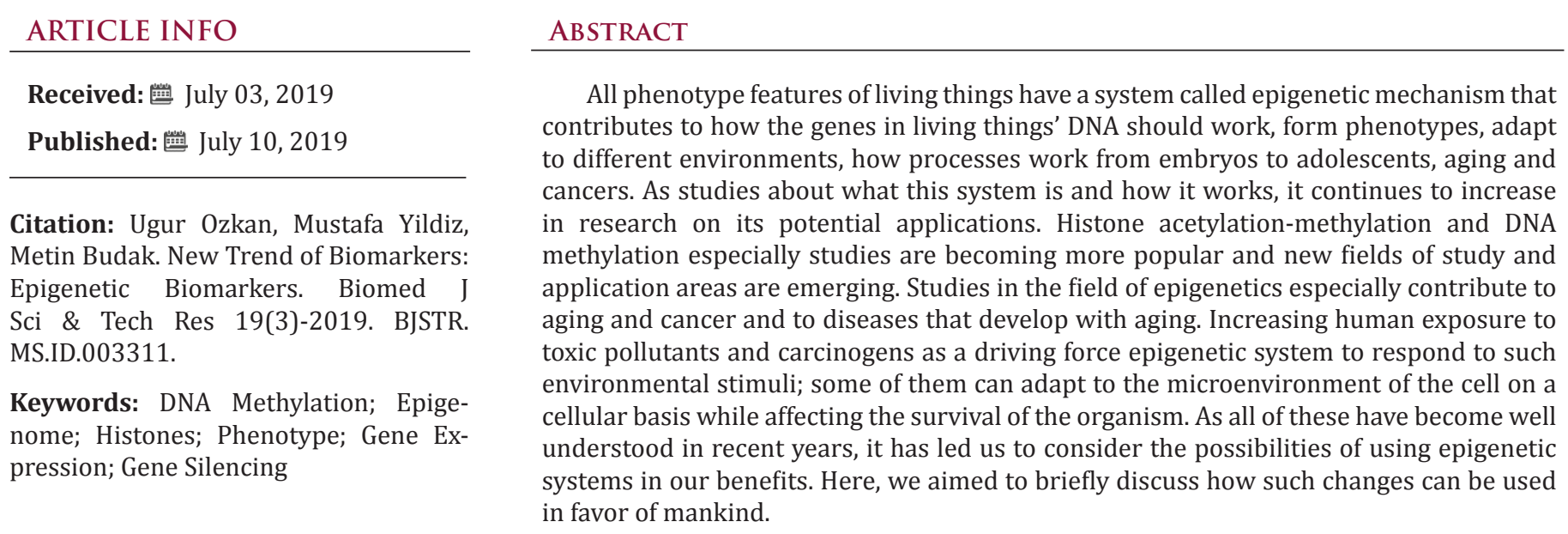

\section{Introduction}

All macromolecular structures are determined by nucleotide sequences in the genome. However, there is another mechanism that determines gene expression and can be transferred from cell to cell. These changes are often called epigenetic. During the generation of this code, DNA sequence is not changed in any way. The most common epigenetic changes are methylation and acetylation of histone proteins and DNA methylation. Methylation changes are a process that can be seen from mammals to bacterial microorganisms, Methylation changes are a process that can be seen from mammals to bacterial microorganisms, developed by an organism as an adaptation method to environmental or intrinsic effects, or used to close genomic regions that are no longer needed in the evolutionary process. It has been shown with scientific studies that these methylated regions can be identified and it is now known that only transcription factors do not control the expression of genes and contribute to epigenetic changes.

DNA methylation is the most commonly studied and best understood ofall the epigeneticmechanisms. Itoccurs the conversion of cytosines to 5 '-methylcytosine through an enzymatic change.
Cytosine methylation in the mammalian genome usually occurs in 5'-CG-3 'binary nucleotides, also called CpG binary nucleotides [1]. Methylation is performed by DNA methyltransferases (DNMT) and DNMT family has four members called as DNMT1, DNMT2, DNMT3A, and DNMT3B. These enzymes are divided into two groups, which protect the methylated region and add new methyl groups. $70 \%$ of all CpG binary nucleotides of the human genome are methylated [2]. The remains are $\mathrm{CpG}$-rich promoter region or regions located in the first exons of the genes, about 200 base pairs in size. These regions are also called $\mathrm{CpG}$ islets and are found in $60 \%$ of all genes [3]. CpG methylation is programmed in the early embryonic period and is maintained in later periods. Since it is effective in regulating gene expression, $\mathrm{CpG}$ methylation is of great importance in performing normal cell functions. DNA methylation plays an important role in the regulation of expression of age-specific or tissue-specific genes by silencing the genes on the inactive $\mathrm{X}$ chromosome [4]. In addition, it is thought to be useful in developing new strategies against aging by calculating the changes in total DNA methylation with various algorithms [5]. It is now known that histone acetylation-deacetylation plays a certain role 
in diseases such as Chronic Obstructive Pulmonary Disease (COPD) and especially cancer. There are also studies that imbalances in acetylation-deacetylation may alter the transcription profile of inflammatory cytokine genes and facilitate COPD development in smokers [6]. In recent years, histone acetyltransferase is thought to play a role in diseases such as cancer, asthma and COPD $[7,8]$. Another example is marker researches in colorectal cancers. SPG20 / ITGA4 / ALX4 gene promoter hypermethylation may help diagnose colorectal cancer without the need for colonoscopy [9]. Doctors with blood samples can diagnose the disease. HRAS, CCND2, and SERPINB5 genes activated by hypomethylation in gastric cancers, CA9 in renal cancers and PAX2 in endometrial cancers are now considered as biomarkers [10-12].

\section{Current Approaches to Epigenetic Therapy}

In light of all this information, after the emergence of the mechanisms of epigenetic changes on cancer and other diseases, Target molecule and marker likelihoods have been investigated in the diagnosis and treatment of diseases. FDA approved chemotherapeutic agents are now being used especially in cancer treatments. For example, Azacitidine and Decitabine in Myelodysplastic syndromes, Vorinostat and Romidepsin in cutaneous T-cell lymphomas, Panobinostat in multiple myelomas, and Belinostat molecule in Peripheral T-cell lymphomas are new chemotherapeutic agents with FDA approval [13].

In addition, epigenetic markers gain importance in monitoring the response to treatments. Treatment is effective in whether DNMT inhibitor treatment is another approach to monitoring genome-wide DNA methylations or not [14]. Therefore, the clinical importance of epigenetic changes in cancer development is increasing and monitoring of the efficacy of cancer treatments is of great importance with appropriate epigenetic markers. Estimation of epigenetic changes in new cancer cells during tumorigenesis may target more specific molecules against these and may provide more effective cancer treatments. As a result, the applicability of such treatments also depends on the ability of respective material to be delivered to the cell and its microenvironment, and material science is involved. There should be adequate studies in this field so that new treatments specific to the cell and person can be applied [15].

In spite of all the knowledge in epigenetic, the development of the above-mentioned epigenetic target therapies in parallel to the science of materials is particularly important for the production of fragment molecules in order to be applied appropriately in living systems. Although our general knowledge increases day by day about epigenetic mechanisms which their applicability must be specific to the individual so that the efficacy of the treatments is appropriate for the disease. Although it is not far to think that epigenetic-based therapies and biomarkers will take place in the near future as well as usual treatments and it gives hope for both patients and specialists.

\section{References}

1. Ramsahoye BH, Biniszkiewicz D, Lyko F, Clark V, Bird AP, et al. (2000) Non-CpG methylation is prevalent in embryonic stem cells and may be mediated by DNA methyltransferase 3a. Proc Natl Acad Sci U S A. 97: 5237-5242.

2. Ehrlich M, Gama-Sosa MA, Huang LH, Midgett RM, Kuo KC, et al. (1982) Amount and distribution of 5-methylcytosine in human DNA from different types of tissues or cells. Nucleic Acids Res 10: 2709-2721.

3. Antequera F, Bird A (1993) Number of CpG islands and genes in human and mouse. Proc Natl Acad Sci U S A. 90: 11995-11999.

4. Plass C, Soloway PD (2002) DNA methylation, imprinting and cancer. Eur J Hum Genet 10: 6-16.

5. Gillespie SL, Hardy LR, Anderson CM (2019) Patterns of DNA methylation as an indicator biological aging: State of the science and future directions in precision health promotion. Nurs Outlook S0029-6554(19): 3005030058.

6. Szulakowski P, Crowther AJ, Jiménez LA, Donaldson K, Mayer R, et al. (2006) The effect of smoking on the transcriptional regulation of lung inflammation in patients with chronic obstructive pulmonary disease. Am J Respir Crit Care Med 174: 41-50.

7. Ito K, Ito M, Elliott WM, Cosio B, Caramori G, et al. (2005) Decreased histone deacetylase activity in chronic obstructive pulmonary disease. $\mathrm{N}$ Engl J Med 352: 1967-1976.

8. Ghizzoni M, Haisma HJ, Dekker FJ (2009) Reactivity of isothiazolones and isothiazolone-1-oxides in the inhibition of the PCAF histone acetyltransferase. Eur J Med Chem 44: 4855-4861.

9. Foroughi R, Chavoshei S, Ashoori H, Mohammad Ganji S, Azizi Tabesh, et al. (2016) Evaluation of new epigenetic markers SPG 20, ITGA 4 and ALX 4 in plasma of colorectal cancer patients. EJPMR 3: 184-189.

10. Oshimo Y, Nakayama H, Ito R, Kitadai Y, Yoshida K, et al. (2003) Promoter methylation of cyclin D2 gene in gastric carcinoma. Int J Oncol 23: 16631670 .

11. Wilson AS, Power BE, Molloy PL (2007) DNA hypomethylation and human diseases. Biochim Biophys Acta 1775: 138-162.

12. Wu H, Chen Y, Liang J, Shi B, Wu G, et al. (2005) Hypomethylationlinked activation of PAX2 mediates tamoxifen-stimulated endometrial carcinogenesis. Nature 438: 981-987.

13. Ansari J, Shackelford RE, El-Osta H (2016) Epigenetics in non-small cell lung cancer: From basics to therapeutics. Transl Lung Cancer Res 5: 155171.

14. Teixeira SR, Abreu CM, Parkes L, Davies J, Yao S, et al. (2019) Direct monitoring of breast and endometrial cancer cell epigenetic response to DNA methyltransferase and histone deacetylase inhibitors. Biosens Bioelectron 141: 111386.

15. Krüger-Genge A, Mauger O, Storsberg J, Schmidt C (2019) Epigeneticsshedding light on the path ahead for material sciences. Diseases 7: E43. 


\section{ISSN: 2574-1241}

DOI: 10.26717/BJSTR.2019.19.003311

Mustafa Yildiz. Biomed J Sci \& Tech Res

(C) (i) This work is licensed under Creative

Submission Link: https://biomedres.us/submit-manuscript.php

\begin{tabular}{ll} 
BIOMEDICAL & Assets of Publishing with us \\
RESEARCHES & - Global archiving of articles \\
& - Immediate, unrestricted online access \\
\hline hittps://biomedres.us/
\end{tabular}

